\title{
Gênero digital Wiki e a produção coletiva de texto
}

\author{
Estêvão Domingos Soares de Oliveira ${ }^{1}$, Vinícius Varella Ferreira ${ }^{2}$ \\ ${ }^{1}$ Universidade Federal da Paraíba/PPGI/UFPBVirtual \\ ${ }^{2}$ Universidade Federal de Pernambuco/PPGE/UFPB Virtual. \\ estevaodso@gmail.com, viniciusvarella@ig.com.br
}

\begin{abstract}
This article aims to investigate how the collective production of text occurs through the use of Wiki in Moodle platform UFPB Virtual in an undergraduate course in distance mode. Following this theme, we wondered about Web 2.0 and its tools can assist the learning of text production students. We chose the Wiki feature because it is a tool / genre that requires the interaction between subjects and colaboratividade when collective production of text. The results are given from the analysis of a text produced by the students of polo in Duas Estradas, Paraiba in the State.
\end{abstract}

Resumo. Este artigo visa investigar como ocorre a produção coletiva de texto através do uso do Wiki na plataforma Moodle da UFPB Virtual, em um curso de graduação na modalidade à distância. Seguindo nesta temática, nos questionamos sobre como a Web 2.0 e suas ferramentas podem auxiliar o aprendizado da produção de texto dos alunos. Escolhemos o recurso Wiki por se tratar de uma ferramenta/gênero que requer a interação e colaboratividade entre os sujeitos no momento de produção coletiva de texto. Os resultados se deram a partir da análise de um texto produzido pelos alunos do polo em Duas Estradas, no Estado da Paraiba.

\section{Introdução}

Nas últimas décadas muitas transformações ocorreram nos segmentos da comunicação e tecnologia, modificando culturalmente nossa sociedade. Neste contexto, o uso da internet e das novas tecnologias, conforme Lévy (1993; 1996; 1999) e Ramal (2002), trouxeram mudanças no nosso dia a dia, pois com elas podemos obter informações mais rápidas e em tempo real, conversar com pessoas que estejam em qualquer lugar do mundo (online ou off-line), estudar, trabalhar e ainda utilizá-la como fonte de pesquisas.

Nesta direção, surgem novos conceitos tais como o de Ciberespaço e de Cibercultura. Segundo Lévy (1999), o termo Ciberespaço é "o espaço de comunicação aberto pela interconexão mundial dos computadores e das memórias dos computadores". Entendemos que o Ciberespaço é o lugar onde circulam as informações por meio de textos, imagens, ícones diversos. Observamos, desta forma, que a expressividade por meio de textos, muitas vezes produzidos de modo coletivo e colaborativo, faz com que os conhecimentos se propaguem ainda mais pelo meio virtual.

Sob esta ótica, nos propomos a investigar neste artigo as práticas de produção de texto de forma coletiva e colaborativa, mais especificamente sobre a ferramenta denominada $W i k i$ - gênero digital específico da educação a distância. Sendo assim, o 
objetivo deste artigo é investigar como ocorre a produção coletiva de texto com o uso do Wiki na plataforma Moodle da UFPB Virtual, em um curso de graduação em EaD.

Vejamos a seguir a metodologia adotada para as análises e descrição dos resultados e posteriormente a discussão sobre os principais fundamentos teóricos que norteiam esta pesquisa e finalizamos pela apresentação dos resultados e as conclusões a que chegamos sobre os dados coletados.

\section{Metodologia}

Iniciamos selecionando o curso de Letras, pois os alunos precisam ter domínio da prática de produção escrita de texto. Em um segundo momento, selecionamos disciplinas do primeiro semestre, pois como os alunos são ingressos no curso ainda não tinham contato com o gênero Wiki, sem a influência de conceitos pré-construídos sobre a ferramenta. Das seis disciplinas do primeiro período apenas a de Introdução a Educação a Distância trabalhava com o Wiki, por esta razão, ela foi selecionada para análise. A escolha pelo Wiki se deu pelo fato de ser um gênero/ferramenta digital que propõe a produção escrita de forma colaborativa. Dos 23 polos atendidos por esta disciplina escolhemos o de Duas Estradas que fica no Estado da Paraíba. A escolha por este polo se deu por apresentar maior interação entre os alunos.

Selecionamos as colaborações dos quatro primeiros alunos que participaram desta produção de texto e fizemos uma análise comparativa entre suas contribuições e o texto final construído coletivamente, que teve como título: "Utilizando o Wiki: o trabalho colaborativo em comunidades virtuais". Dessa forma, verificamos as seguintes questões: a) A contribuição escrita de cada aluno no texto tinha relação direta com o tema proposto? b) A contribuição postada por cada aluno tinha relação direta com as propostas apresentadas pelos outros alunos que escreveram antes de sua postagem, dando sequencia ao texto? c) Houve coerência e a coesão textual entre as ideias postadas por cada aluno?

\section{Wiki: ferramenta da web como gênero virtual de produção de texto}

Gênero virtual é uma nova modalidade de gênero textual, que surgiu com a ascensão da internet, dentro do que chamamos de hipertexto. A partir das tecnologias disponíveis no Ciberespaço e com o desenvolvimento da Cibercultura, iniciamos uma nova forma de comunicação online, um modelo mais interacional, interativo, coletivo e colaborativo.

Nesta direção o Wiki busca dar conta desta tarefa de produção escrita em que os sujeitos/autores produzam um texto, de forma assíncrona (ou seja, que não estejam online no mesmo momento, mas que possam visualizar as contribuições de todos os colegas quando estiver online no ambiente em que o texto foi postado) assim como, podem contribuir com as ideias expostas de tal modo que o tema proposto para produção do texto seja amplamente discutido e que possa tornar-se um único texto.

Para que a produção coletiva a partir desta ferramenta seja um sucesso, dependese exclusivamente do engajamento dos alunos/usuários que devem se sentir motivados a intervirem na produção do texto, da possibilidade de corrigir uma informação que esteja inadequada/errada ou fora de contexto, ampliar um texto ainda na fase inicial de esboço, ou ainda editar um conjunto de frases desarticuladas, buscando a coesão e coerência textual. 


\section{Texto: coesão e coerência}

Do ponto de vista da Lingüística, é difícil definir o que é texto (Rojo, 2003; VAL, 1991), pois sua noção é algo amplo, sem padrões específicos nem paradigmas fechados, entretanto podemos entendê-lo como qualquer forma de expressão das idéias de um autor.

O texto possui uma variável, tanto no seu tamanho quanto na sua estrutura, mas o fundamental para que seja compreendido, é que apresente alguns aspectos formais, tais como a coesão e a coerência para que o mesmo tenha sentido e forma.

Koch (2008) conceitua coesão como sendo o "fenômeno que diz respeito ao modo como os elementos lingüísticos presentes na superfície textual encontram-se interligados entre si, por meio de recursos também linguísticos". Ainda de acordo com a mesma autora $(2008$, p.52), "coerência diz respeito ao modo como os elementos subjacentes à superfície textual vêm a construir, na mente dos interlocutores uma configuração veiculadora de sentidos".

Para exemplificar a importância destes elementos na construção de textos, destacamos um fragmento construído pelos alunos no Wiki e faremos uma análise mais detalhada na sessão de Análise e Resultados.

\section{Quadro 1: Fragmentos do Wiki dos alunos do Polo Duas Estradas/PB.}

$O$ trabalho colaborativo em comunidades virtuais de aprendizagem

Comunidades virtuais de aprendizagem são elaboradas para que o conhecimento de determinadas áreas da educação seja estudado e enriquecido colaborativamente através da interação contínua de seus participantes. Esta interação acontece quando compartilhamos o que estamos aprendendo e recebemos de nossos colegas o que aprenderam, utilizando assim uma forma construtivista de elaborarmos novos conhecimentos.

Os diálogos devem ser coerentes usando as regras de Netiqueta, tendo certa ética ao direcionamos com os colegas, tutores e professores do curso. Podemos fazer uso dos emoticons (as expressões faciais de como está os nossos sentimentos), as palavras devem ser claras para que não surgir dúvidas em relação so seu posicionamento assim terá um bom relacionamento com os participantes. Precisamos ser assíduos e tratar os colegas da sala de aula virtual da mesma forma que gostaria de ser tratado.

É muito importante que existam regras no ambiente virtual, até porque existem pessoas com dificuldades para usar essa nova modalidade de ensino, tem pessoas que tem mais facilidade e fazendo-se uso dessas ferramentas os alunos com menos praticidade se sentirão mais seguro para expor suas idéias e se expressar com mais segurança nos fóruns.

$\mathrm{O}$ ato da colaboração dentro de uma comunidade virtual é de extrema importância, tanto para quem colabora quanto para quem participa da colaboração, é pela interação com alunos e professores, recebendo feedbacks, acrescentando informações concordando ou não com comentáriose argumentos, que desenvolvemos a, auto-aprendizagem, que é fundamental no processo de formação de um aluno virtual.

\section{Análise e resultados: uma questão de interação e colaboratividade na construção de um texto coletivo}

A partir de agora, responderemos as questões abaixo utilizando os dados referentes à produção coletiva de texto realizada por meio do Wiki dos alunos do polo de Duas Estradas/PB da UFPB Virtual.

\section{a) A contribuição escrita de cada aluno no texto tinha relação direta com o tema proposto?}


O Aluno 1 usou a expressão "Comunidades virtuais de aprendizagem" e a palavra "colaborativamente" para fazer referência ao título do texto que foi $\mathbf{O}$ trabalho colaborativo em comunidades virtuais de aprendizagem. $\mathrm{O}$ aluno faz menção à troca de conhecimentos entre os alunos por meio da interação. O Aluno 2 não utilizou nenhuma palavra que estava presente no título da produção textual como o fez o Aluno 1. O que observamos é que o Aluno 2 optou por, na continuidade da ideia anterior exposta pelo Aluno 1, exibir alguns exemplos de como se comportar no ambiente virtual de aprendizagem usando as regras de Netiqueta.

Já o Aluno 3 não fez nenhuma referência ao título, mas preocupou-se em reforçar a ideia do Aluno 2. Sendo assim, o Aluno 3 não falou diretamente sobre trabalho colaborativo, mas mostrou entendimento sobre a questão da interação e preocupação o trabalho colaborativo. Podemos observar que este faz referência ao Fórum que é um lugar de interação e colaboração entre os alunos e com o professor.

No caso do Aluno 4, constatamos que houve a preocupação do mesmo em retomar a discussão e, para isso, lançou mão dos termos presentes no título da proposta de produção textual. Depois o mesmo aluno segue discutindo sobre a colaboração por meio da interação entre os sujeitos (alunos e professores) por meio de feedback, ou seja, por meio de textos escritos. Finaliza sua participação deixando um novo assunto a ser discutido dentro do tema sobre aluno virtual que foi a auto-aprendizagem.

b) A contribuição postada por cada aluno tinha relação direta com as propostas apresentadas pelos outros alunos que escreveram antes de sua postagem, dando sequencia ao texto?

Constatamos que o Aluno 2 optou por exemplificar o que o Aluno 1 havia conceituado e, acrescentando novas informações ao tema, tais como a preocupação com as regras de Netiqueta no processo de interação e colaboração enquanto aluno virtual. No caso do Aluno 3, este deu sequência, de forma bastante superficial, as ideias expostas pelo Aluno 2. Todavia, o Aluno 3 apresenta uma ideia sobre ferramentas de ensino online, mas a trata como se estivesse retomando uma ideia anterior, enquanto que a mesma ainda não havia sido tratada anteriormente.

O Aluno 4, sente a necessidade de retomar o tema principal e seu parágrafo fica diretamente ligado ao primeiro. Este fato nos remete a ideia de que, possivelmente, o Aluno 4 percebeu que os alunos anteriores estavam fugindo da temática proposta.

\section{c) Houve coerência e a coesão textual entre as ideias postadas por cada aluno?}

Ao analisarmos as quatro primeiras colaborações do texto coletivo, verificamos que predominou a ausência de elementos que conectasse a ideia de um parágrafo ao outro, dando a impressão de que o texto foi feito de recortes, pois na falta de elementos coesivos, tais como as conjunções, acaba por descaracterizar a ideia do que é um texto.

O Aluno 2 busca dar exemplos às contribuições teóricas do Aluno 1, contudo, faltou um conectivo para ligar os dois parágrafos e fazer a coerência entre a teoria (parágrafo 1) e os exemplos (parágrafo 2). Também não houve o uso de conectivos entres os outros parágrafos, mostrando que cada aluno preocupou-se mais em dar sua própria ideia sobre o tema proposta para a produção, do que dar continuidade textual a produção, o que acarretou no comprometimento com a coerência textual. Levantamos a 
hipótese de que houve falta de revisão textual por parte dos alunos antes de iniciarem a sua escrita e ao término da mesma.

\section{Conclusão}

Concluímos que produzir um texto coletivo e colaborativo, exige muito mais do que simplesmente domínio do conteúdo. Precisamos, antes, entender o verdadeiro propósito do que é produção coletiva e como podemos colaborar no desenvolvimento das ideias propostas.

No Wiki, embora o autor faça valer sua individualidade como autor propondo seu estilo de escrita (BAKHTIN, 2000), deve existir, inicialmente, a preocupação com a coerência e a coesão textual, pois partindo dos pressupostos de Kock $(2003$; 2008) para que o texto seja de fato um texto ele deve ser coerente e coeso.

Outro aspecto importante está na revisão textual que identificamos como fator importante de interação entre as ideias já expostas e as que serão acrescentadas no texto e, ainda, uma forma de colaborar com a escrita dos outros alunos em prol de um texto mais consistente e inteligível. Se não houver a interação, a colaboração e o domínio sobre o conteúdo, ficamos fadados a um conjunto de fragmentos de textos, nos quais muitas idéias ficarão repetidas, incompletas, ou até mesmo, desconexas. Ou seja, percebemos que ainda existe uma fragilidade no Wiki quanto a coesão e coerência textual.

Podemos apontar ainda que embora a principal função do Wiki seja a de propor a produção coletiva de texto, precisamos desenvolver antes a noção de colaboratividade e interação entre os alunos, para que, somente depois deste entendimento, possamos fazer uso do Wiki em sua função de produção coletiva de texto, assim como a noção de coesão e coerência textual como condição mínima para que, de fato, um texto seja reconhecido como tal.

\section{Referências}

BAKHTIN, Mikhail. Estética da criação verbal. Trad. Maria Ermantina Galvão. São Paulo: Martins Fontes, 2000.

KOCH, Ingedore Grunfeld Villaça. O texto e a construção dos sentidos. São Paulo: Contexto, 2008.

LÉVY, Pierre. As tecnologias da inteligência. Rio de Janeiro: Editora 34, 1993.

. Cibercultura. Trad. Carlos Irineu da Costa. São Paulo: Editora 34, 1999.

. O que é virtual. Rio de Janeiro: Editora 34, 1996.

RAMAL, J. Educação na cibercultura: hipertextualidade, leitura, escrita e aprendizagem. Porto Alegre: Artes Médicas, 2002.

ROJO, Roxane. Revisitando a produção de textos na escola. In.: VAL, Maria da Graça Costa (org.). Reflexões sobre práticas escolares de produção de texto: o sujeito-autor. Belo Horizonte: Autêntica, 2003. 